\title{
Minimally invasive lateral trans-psoas approach for tuberculosis of lumbar spine
}

Nitin Garg

Department of Neurosurgery, Bhopal Memorial Hospital and Research Centre, Bhopal, Madhya Pradesh, India

\section{A B S T R A C T}

Anterior, posterolateral and posterior approaches are used for managing lumbar tuberculosis. Minimally invasive methods are being used increasingly for various disorders of the spine. This report presents the utility of lateral trans-psoas approach to the lumbar spine (LS) using minimal access techniques, also known as direct lateral lumbar interbody fusion in 2 cases with tuberculosis of LS. Two patients with tuberculosis at L2-3 and L4-5 presented with back pain. Both had destruction and deformity of the vertebral body. The whole procedure comprising debridement and placement of iliac crest graft was performed using tubular retractors and was augmented by posterior fixation using percutaneous transpedicular screws. Both patients recovered well with no significant procedure related morbidity. Post-operative computed tomography scans showed appropriate position of the graft and instrumentation. At follow-up, both patients are ambulant with no progression of the deformity. Minimal access direct lateral transpsoas approach can be used for debridement and reconstruction of ventral column in tuberculous of Lumbar spine. This paper highlights the growing applications of minimal access surgery for spine.

Key words: Direct lateral lumbar interbody fusion, lateral trans-psoas approach, minimally invasive approach, spondylodiscitis, tuberculosis

\section{INTRODUCTION}

Tuberculosis of the spine is a common form of extra-pulmonary tuberculosis. Surgery is required in those with significant neurological deficits, deformity, persistent pain, progression of disease and inconclusive diagnosis. ${ }^{[1]}$ Lumbar spine can be accessed by the conventional retroperitoneal approach as well as minimal access methods like mini-anterior lumbar interbody fusion (ALIF) ventrally, transforaminal approach (transforaminal lumbar interbody fusion [TLIF]) posterolaterally and posterior transpedicular approach. Minimal access lateral trans-psoas approach also known as direct lateral lumbar interbody fusion (DLIF) is a minimally invasive approach to the ventro-lateral aspect of the lumbar spine (LS) being used more often for adult degenerative spinal deformity. We describe the feasibility

\begin{tabular}{|l|l|}
\hline \multicolumn{2}{|c|}{ Access this article online } \\
\hline Quick Response Code: & Website: \\
\hline & www.ijns.in \\
\cline { 2 - 3 } & \\
\hline
\end{tabular}

of this approach for managing tuberculosis of the LS in two patients. To the best of our knowledge, this is first such report of using the DLIF approach for tubercular spondylodiscitis of the LS.

\section{CASE REPORTS}

Case 1

The first case we present here is 70 -year-old female patient who presented with back pain of 4 months duration, with severity increasing since 1 month associated with weakness in both lower limbs (power Grade 4/5) of 15 days duration. Magnetic resonance imaging (MRI) LS spine revealed partial destruction of L2-3 vertebrae with enhancement and significant prevertebral and epidural granulation tissue causing compression of the thecal sac. Findings were suggestive of tuberculosis of the spine. Computed tomography (CT) scan revealed the extent of bony destruction with focal kyphosis [Figure 1].

Case 2

The second case is a 65 -year-old female presenting with low back pain of 3 months duration with inability to sit or stand. There was no neurological deficit. Her MRI scan revealed destruction of L4 body with edema and

Address for correspondence: Dr. Nitin Garg,

Department of Neurosurgery, Bhopal Memorial Hospital and Research Centre, Near Karond Square, Bhopal - 462 038, Madhya Pradesh, India.

E-mail: drnitingarg@hotmail.com 
enhancement of L4 and L5 bodies and intervening disc with paravertebral and epidural enhancing granulation tissue. CT scan revealed significant destruction of the L4 body [Figure 2].

\section{PROCEDURE}

The decision to reconstruct the ventral column was taken in view of significant vertebral body destruction.

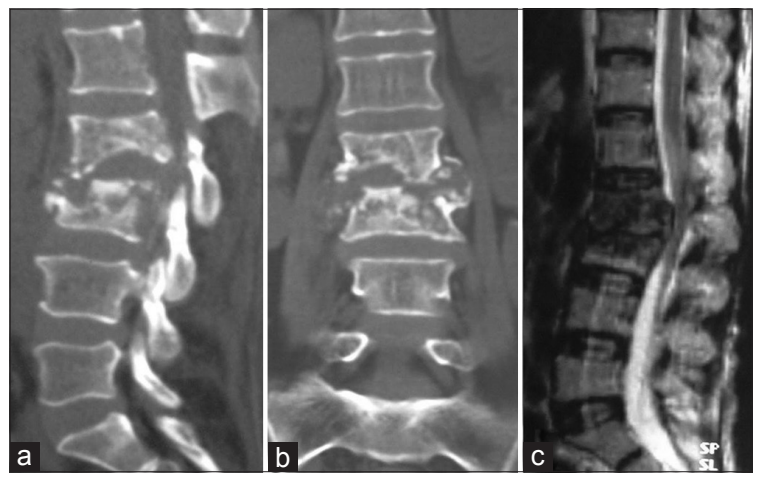

Figure 1: Pre-operative scans of Case 1. (a and b) Computed tomography scans with sagittal and coronal reconstructions with irregular margins of involved bone. (c) Magnetic resonance imaging T2W sagittal scan with focal kyphosis and ventral thecal sac compression
Uninvolved adjacent vertebral body segments were used for fixation. This was performed by percutaneous transpedicular screws in prone position in same sitting.

DLIF was performed using tubular retractors $\left(\mathrm{DLIF}^{\circledR}\right.$ retractor system, Medtronics Inc., USA) to access the ventrolateral aspect of the LS. The patient is positioned in right lateral position [Figure 3a]. It is important to confirm the adequacy of lateral flexion using a lateral X-ray to be

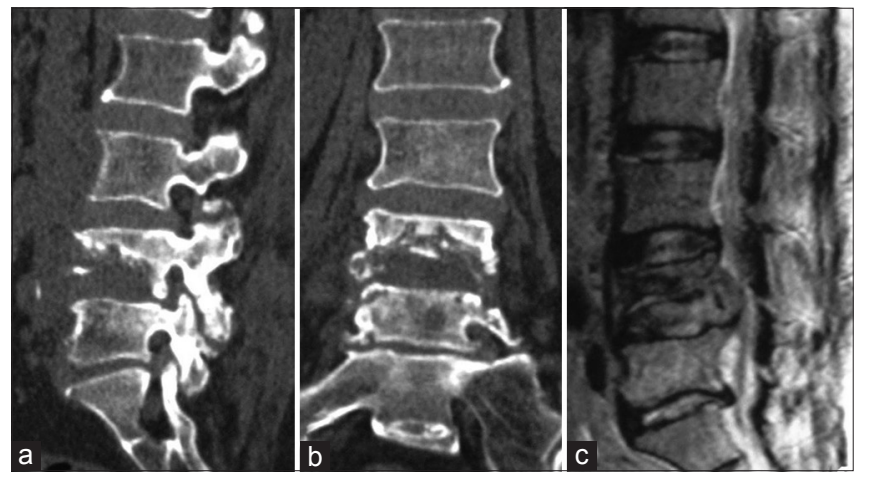

Figure 2: Pre-operative scans of Case 2 ( $a$ and b) Computed tomography scans showing destruction of $L 4$ vertebral body. (c) Magnetic resonance imaging T2W sagittal scan with ventral granulation tissue and thecal sac compression
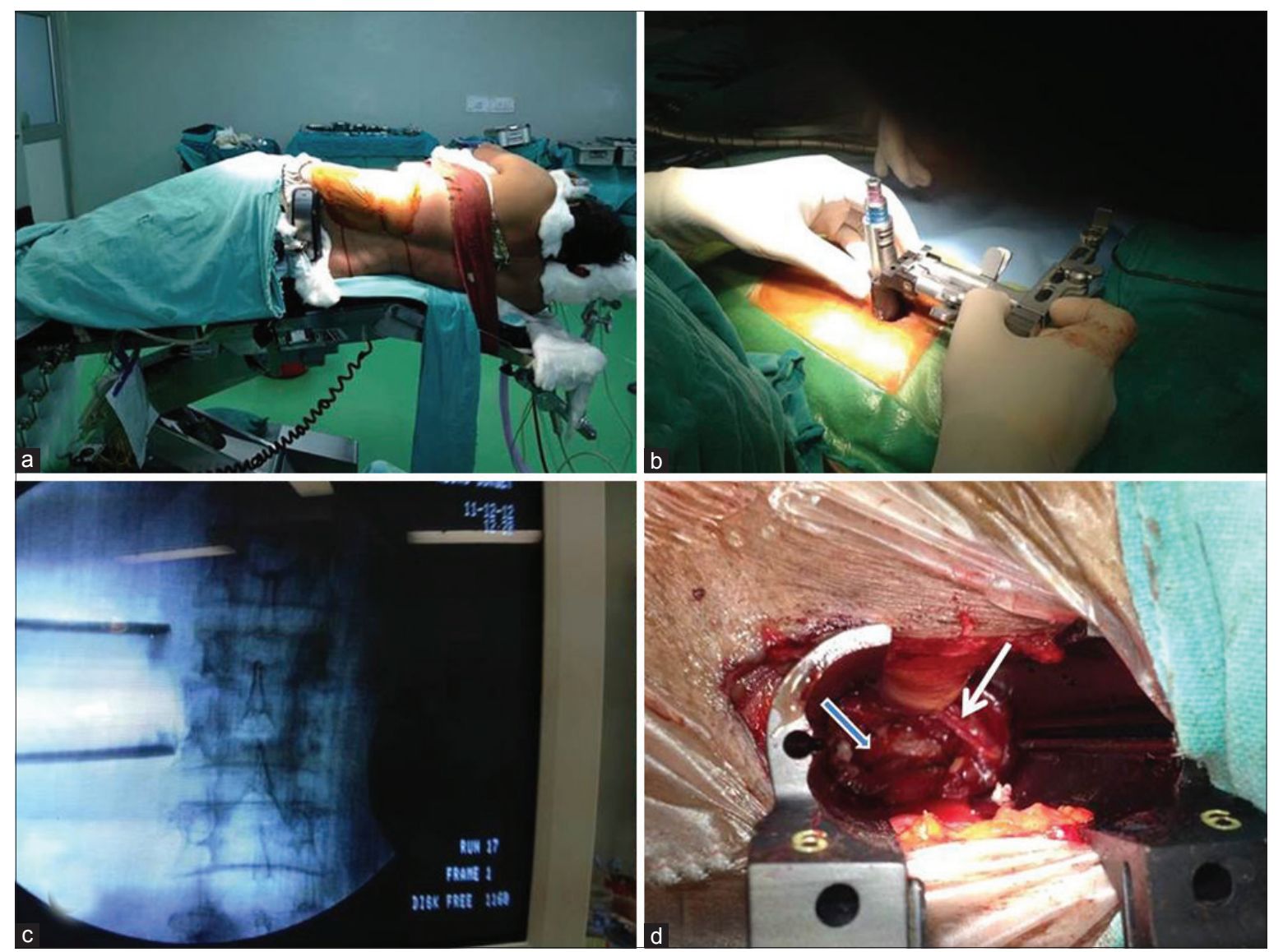

Figure 3: Intra-operative images (a) Lateral position (b) Retractor being positioned (c) Confirmation of appropriate position of retractor blades on C-arm (d) retractor expanded. Iliac crest graft placed (bold arrow) and genitofemoral nerve preserved (arrow) 
sure that the iliac crest does not interfere in accessing the relevant level of the LS. If the crest comes in line with the area of interest, then either an iliac osteotomy may be done or another approach performed. Under C-arm guidance, appropriate skin incision is marked. After incising the skin, sequential dissection of abdominal muscles is done until pre-peritoneal space is reached. Blunt retroperitoneal dissection is performed until the lateral surface of psoas muscle is reached. The smallest tubular dilator is positioned [Figure 3b] and level confirmed with C-arm [Figure 3c]. Electromyography (EMG) recording is done from the relevant muscles to rule out proximity of lumbar plexus root to avoid injury. C-arm guidance is used intermittently to be sure about the level and trajectory. The psoas is dissected along the length of its fibres with intermittent EMG monitoring of L2 and L3 roots (in Case 1) and L4 and L5 roots (in Case 2). The genitofemoral nerve was visualized in Case 1 and preserved [Figure 3d]. The retractor blades (length from $90 \mathrm{~mm}$ to $170 \mathrm{~mm}$ ) are positioned after splitting the muscle fibres, disc space is entered and debridement of necrotic and purulent material done. Thorough debridement was done till the healthy bone was encountered. Appropriate sized iliac
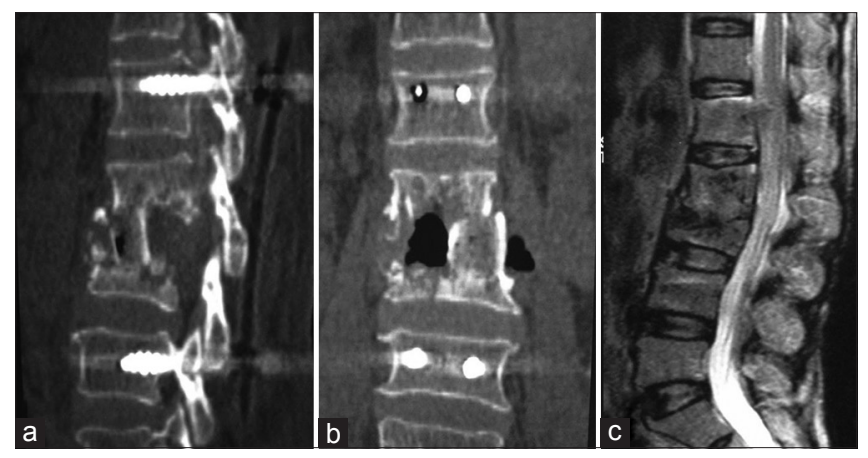

Figure 4: Case 1 - ( $a$ and b) Post-operative computed tomography scan with graft in position and correction of deformity. (c) At 6 months follow-up magnetic resonance imaging with significant healing crest autograft $(1.9 \mathrm{~cm}$ in Case 1 and $2.1 \mathrm{~cm}$ in Case 2) was placed for fusion [Figure $3 \mathrm{~d}$ ]. The final image was confirmed on $\mathrm{C}$-arm. After confirming the proper positioning of the graft, the table was straightened thereby helping to keep the graft adequately compressed and correcting the scoliosis. The wound is closed in layers. Fixation is done using percutaneous transpedicular screws in prone position in the same sitting (Longitude ${ }^{\circledR}$ (Case 1) and Sextant ${ }^{\circledR}$ (Case 2) System, Medtronics Inc., USA). The screws were inserted into adjacent healthy vertebral bodies. Involved vertebral bodies were not instrumented to avoid risk of screw pull-out.

Post-operatively, both patients recovered well with no neurological deficits. Case 2 had difficulty extending the left hip for a week due to spasm of the psoas which responded well to muscle relaxants and subsided gradually. By $3^{\text {rd }}$ day, patients were made to sit with weight bearing. Post-operative CT scan showed proper position of the graft and screws [Figures $4 \mathrm{a}, 4 \mathrm{~b}$, $5 \mathrm{a}$ and $5 \mathrm{~b}]$. There was no post-operative ileus and oral feeding started from $1^{\text {st }}$ post-operative day. Both patients were ambulant by $2^{\text {nd }}$ week with support and at 3 months follow-up, are walking independently. Both patients have been on anti-tubercular pharmacotherapy. At follow-up of 9 and 12 months, there is significant healing of the disease and no radiological progression of deformity [Figures $4 c, 5 c$ and d].

\section{DISCUSSION}

Various approaches have been used to achieve debridement and interbody fusion for tuberculosis of LS. ${ }^{[2-4]}$ The approaches range from conventional retroperitoneal method to mini-ALIF, TLIF and posterior transpedicular approach. The ventral approaches have risk of morbidity due to post-sympathectomy syndrome,
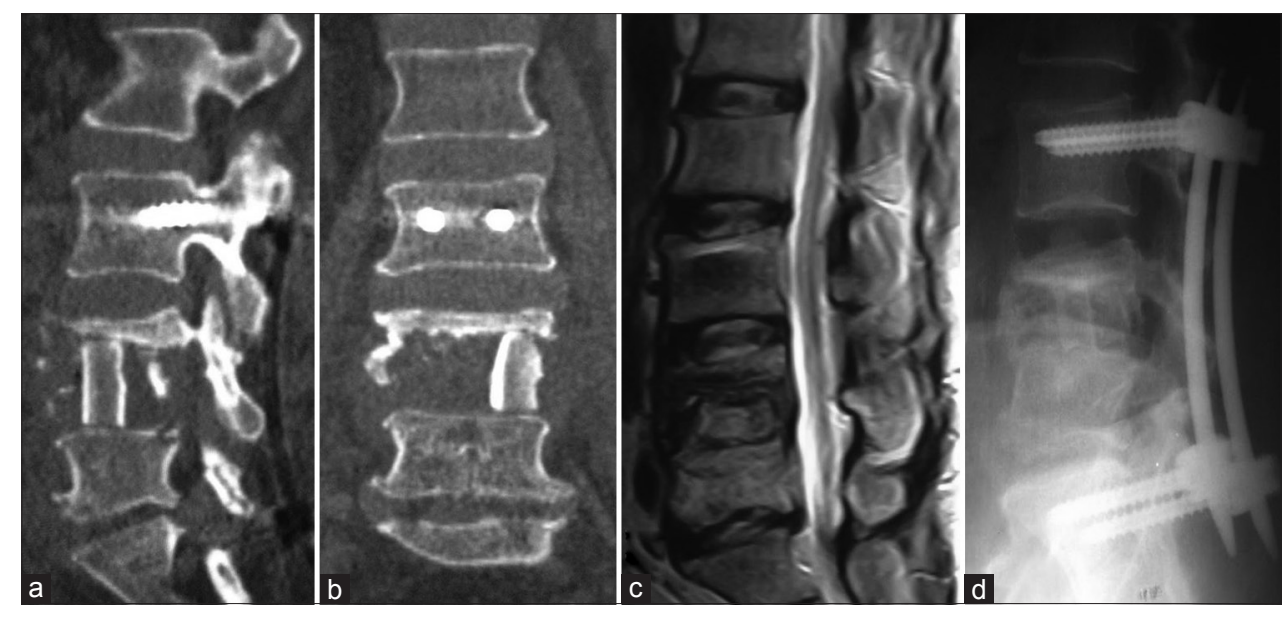

Figure 5: Case 2 - (a and b) Post-operative computed tomography scan with graft in- situ. (c) At 3 months follow-up magnetic resonance imaging. (d) At 12 months follow-up X-ray showing bony regeneration and fusion 
retrograde ejaculation, visceral and vascular injury ${ }^{[5]}$ and need of an access surgeon. Posterior transpedicular approach is useful mainly in those without significant vertebral body collapse, ${ }^{[4]}$ and those requiring limited debridement only. Few case reports utilizing minimally invasive surgery (MIS) approaches have been described for managing tuberculosis of LS as percutaneous aspiration, ${ }^{[6]}$ endoscopic suction and drainage ${ }^{[7]}$ with supplemental percutaneous transpedicular fixation. ${ }^{[8]}$ These have limitation in those with sequestered bone, thick pus and granulation tissue. TLIF is used mainly for sagittal deformity correction, and is increasingly being performed using MIS techniques. ${ }^{[9]}$ It has also been described in tuberculosis with good results. ${ }^{[3]}$ It has its own limitations due to limited size of graft that can be placed between the exiting and traversing roots (maximum size of TLIF cage is $14 \mathrm{~mm}$ ), the risk of neural injury due to retraction of roots and the need for removal of intact healthy posterior elements in tuberculosis, which is a predominantly ventral disease. In addition, the edges of healthy, intact bone may not be visible directly and completely due to irregular margins [Figures 1 and 2], thereby limiting the ability of proper placement and approximation of the graft with bone surfaces. To place a graft in proximity with these uneven edges from posterior approach is challenging and may result in suboptimal contact between the graft and bone. Use of expandable cages can help overcome this problem but are costly. A ventral or ventrolateral approach is helpful to place the graft under direct vision.

The minimally invasive lateral transpsoas approach to the LS, also known as DLIF, is a MIS approach to access the ventrolateral aspect of the LS. This was first described by Ozgur and Pimenta et al. in 2001[10] and since then has been increasingly used for managing degenerative disc disease and degenerative scoliosis of the LS. ${ }^{[11]}$ Some case reports of DLIF approach for managing osteomyelitis and discitis have also been described. ${ }^{[12,13]}$ It combines the benefit of providing ventral access to debride the necrotic bone without morbidity of ALIF procedure, ${ }^{[5,14]}$ preparation of the margins of the bone, placing the bone graft directly under vision and no limitation in the size of the graft. ${ }^{[15]}$ Biomechanical studies have shown equivalency between DLIF and anterior approaches to the LS. ${ }^{[16]}$

DLIF approach has some limitations. The number of levels that can be accessed are limited to L2-3, L3-4 and L4-5. L1-2 and L5-S1 cannot be accessed due to rib cage and iliac crest respectively. Electrophysiological monitoring is required to avoid retraction injury to the exiting roots of lumbar plexus by retractor blades. Some studies have reported high approach related morbidity due to retraction of the psoas and pressure on the adjacent nerves and persistent hypoesthesia on the anterolateral aspect of the thigh. ${ }^{[11]}$ Separate dedicated instrumentation is required to perform this technique.

The decision to use MIS DLIF approach over conventional and other MIS approaches in both these patients was mainly based upon poor general condition of patient, the need for limited debridement of the disc space and adjacent necrotic bone, ventral column reconstruction more than $14 \mathrm{~mm}$ in length and uneven margins of involved bone. Following debridement and fusion with iliac crest graft, fixation was done using percutaneous transpedicular screws (Longitude ${ }^{\circledR}$ and Sextant ${ }^{\circledR}$ System, Medtronics Inc., USA) in prone position in same sitting. The number of levels to be incorporated in the construct vary from 2 levels on either side of involved vertebrae, ${ }^{[17]}$ one level, ${ }^{[18,19]}$ to short segment mono-segmental fixation incorporating only the diseased vertebrae. ${ }^{[3]}$ Even laminar hooks have been used with good results and no deformity progression. ${ }^{[20]}$ In the two cases presented, the involved vertebrae were not included in the construct in view of significant destruction in Case 1 and risk of screw loosening due to edema in involved vertebrae in both the cases. Circumferential fusion by combining both anterior and posterior approaches can be achieved using purely MIS methods.

\section{CONCLUSION}

MIS DLIF is a minimally invasive alternative approach that can be used in the select group of patients of lumbar tuberculosis. All aims of adequate debridement and reconstruction of ventral column can be achieved using this method. Further studies with a larger patient group are required for assessing the long term efficacy of this method and considering this as a standard method of treatment.

\section{REFERENCES}

1. Tuli SM. Tuberculosis of the spine: A historical review. Clin Orthop Relat Res 2007;460:29-38.

2. Pu X, Zhou Q, He Q, Dai F, Xu J, Zhang Z, et al. A posterior versus anterior surgical approach in combination with debridement, interbody autografting and instrumentation for thoracic and lumbar tuberculosis. Int Orthop 2012;36:307-13.

3. Kandwal P, Garg B, Upendra B, Chowdhury B, Jayaswal A. Outcome of minimally invasive surgery in the management of tuberculous spondylitis. Indian J Orthop 2012;46:159-64.

4. Lee BH, Lee HM, Kim TH, Kim HS, Moon ES, Park JO, et al. Transpedicular curettage and drainage of infective lumbar spondylodiscitis: Technique and clinical results. Clin Orthop Surg 2012;4:200-8.

5. Hrabalek L, Adamus M, Gryga A, Wanek T, Tucek P. A comparison of complication rate between anterior and lateral approaches to the 
lumbar spine. Biomed Pap Med Fac Univ Palacky Olomouc Czech Repub 2012;156:1-6.

6. Hanaoka N, Kawasaki Y, Sakai T, Nakamura T, Nanamori K, Nakamura E, et al. Percutaneous drainage and continuous irrigation in patients with severe pyogenic spondylitis, abscess formation, and marked bone destruction. J Neurosurg Spine 2006;4:374-9.

7. Ito M, Sudo H, Abumi K, Kotani Y, Takahata M, Fujita M, et al. Minimally invasive surgical treatment for tuberculous spondylodiscitis. Minim Invasive Neurosurg 2009;52:250-3.

8. Ringel F, Stoffel M, Stüer C, Meyer B. Minimally invasive transmuscular pedicle screw fixation of the thoracic and lumbar spine. Neurosurgery 2006;59 (4 Suppl 2):ONS361-6.

9. Cheng JS, Park P, Le H, Reisner L, Chou D, Mummaneni PV. Short-term and long-term outcomes of minimally invasive and open transforaminal lumbar interbody fusions: Is there a difference? Neurosurg Focus 2013;35:E6.

10. Ozgur BM, Aryan HE, Pimenta L, Taylor WR. Extreme Lateral Interbody Fusion (XLIF): A novel surgical technique for anterior lumbar interbody fusion. Spine J 2006;6:435-43.

11. Arnold PM, Anderson KK, McGuire RA Jr. The lateral transpsoas approach to the lumbar and thoracic spine: A review. Surg Neurol Int 2012;3 Suppl 3:S198-215.

12. Rodgers WB, Gerber EJ, Patterson J. Intraoperative and early postoperative complications in extreme lateral interbody fusion: An analysis of 600 cases. Spine (Phila Pa 1976) 2011;36:26-32.

13. Youssef JA, McAfee PC, Patty CA, Raley E, DeBauche S, Shucosky $E$, et al. Minimally invasive surgery: Lateral approach interbody fusion: Results and review. Spine (Phila Pa 1976) 2010;35 26 Suppl:S302-11.

14. Benglis DM, Elhammady MS, Levi AD, Vanni S. Minimally invasive anterolateral approaches for the treatment of back pain and adult degenerative deformity. Neurosurgery 2008;63:191-6.

15. DeLuzio KJ, Lucio JC, Rodgers WB. Value and cost in less invasive spinal fusion surgery: Lessons from a community hospital. SAS J 2010;4:37-40.

16. Laws CJ, Coughlin DG, Lotz JC, Serhan HA, Hu SS. Direct lateral approach to lumbar fusion is a biomechanically equivalent alternative to the anterior approach: An in vitro study. Spine (Phila Pa 1976) 2012;37:819-25.

17. Zhang $\mathrm{H}$, Huang $\mathrm{S}$, Guo $\mathrm{H}, \mathrm{Ge} L$, Sheng $B$, Wang $\mathrm{Y}$, et al. A clinical study of internal fixation, debridement and interbody thoracic fusion to treat thoracic tuberculosis via posterior approach only. Int Orthop 2012;36:293-8.

18. Garg B, Kandwal P, Nagaraja UB, Goswami A, Jayaswal A. Anterior versus posterior procedure for surgical treatment of thoracolumbar tuberculosis: A retrospective analysis. Indian J Orthop 2012;46:165-70.

19. Garg N, Vohra R. Minimally invasive surgical approaches in the management of tuberculosis of the thoracic and lumbar spine. Clin Orthop Relat Res 2014;Jan (epub, ahead of print)

20. Kim DJ, Yun YH, Moon SH, Riew KD. Posterior instrumentation using compressive laminar hooks and anterior interbody arthrodesis for the treatment of tuberculosis of the lower lumbar spine. Spine (Phila Pa 1976) 2004;29:E275-9.

How to cite this article: Garg N. Minimally invasive lateral trans-psoas approach for tuberculosis of lumbar spine. Indian $\mathrm{J}$ Neurosurg 2014;3:36-40.

Source of Support: Nil, Conflict of Interest: None declared.

\section{New features on the journal's website}

\section{Optimized content for mobile and hand-held devices}

HTML pages have been optimized of mobile and other hand-held devices (such as iPad, Kindle, iPod) for faster browsing speed.

Click on [Mobile Full text] from Table of Contents page.

This is simple HTML version for faster download on mobiles (if viewed on desktop, it will be automatically redirected to full HTML version)

\section{E-Pub for hand-held devices}

EPUB is an open e-book standard recommended by The International Digital Publishing Forum which is designed for reflowable content i.e. the text display can be optimized for a particular display device.

Click on [EPub] from Table of Contents page.

There are various e-Pub readers such as for Windows: Digital Editions, OS X: Calibre/Bookworm, iPhone/iPod Touch/iPad: Stanza, and Linux: Calibre/Bookworm.

\section{E-Book for desktop}

One can also see the entire issue as printed here in a 'flip book' version on desktops. Links are available from Current Issue as well as Archives pages. Click on View as eBook 